\title{
Stress-induced foliation in the terminus of Variegated Glacier, Alaska, U.S.A, formed during the 1982-83 surge
}

\author{
W. TAD PFEFFER \\ Geophysics Program AK-50, University of Washington, Seattle, Washington 98195, U.S.A.*
}

\begin{abstract}
Two sets of bubble-density foliation, one vertical and transverse to flow and one vertical and parallel to flow, developed in the ice of the terminus lobe of Variegated Glacier, Alaska, during the passage of the final stages of the 1982-83 surge in June and July 1983. The transverse foliation is ubiquitous in the lower part of the terminus lobe affected by the surge, but disappears abruptly over a $5 \mathrm{~m}$ wide zone at the boundary of the surge, as delineated by measurable strain rates during the surge. The ice at the outermost limit of the transverse foliation experienced compressive total strains no greater than -0.10 (logarithmic), but did briefly experience high strain rates, corresponding to compressive stresses in excess of $0.6 \mathrm{MPa}$. It is concluded that the transverse foliation was developed as a consequence of high compressive stress rather than high total strains. Experimental evidence of $\mathrm{Kamb}$ indicates that bubble migration occurs under similar tectonic conditions to those in the terminus lobe during the surge, and that bubble migration is related to stress rather than finite deformation or rotation of pre-existing structures. Bubble migration may be the mechanism by which the transverse foliation developed during the passage of the surge front.
\end{abstract}

\section{INTRODUCTION}

Variegated Glacier, located near Yakutat (Disenchantment Bay), Alaska, surged between January 1982 and July 1983. The geometry and characteristics of the glacier between surges (Bindschadler and others, 1977) as well as the dynamics and overall kinematic behavior during the 1982-83 surge (Kamb and others, 1985; Raymond and others, 1987) have been described elsewhere.

The kinematics of the propagation of surge activity, especially in the terminus lobe of the glacier, was characterized by high velocities $\left(>20 \mathrm{~m} \mathrm{~d}^{-1}\right)$ and high strain rates $\left(>0.1 \mathrm{~d}^{-1}\right)$, and a topographic front which propagated down-glacier as fast-moving ice encountered and activated slow-moving or motionless ice which lay in its path. Velocities and strain rates during the propagation of the surge front into the terminus lobe were observed by daily surveys during June and July 1983. These have been discussed by Raymond and others (1987) (referred to here as R87). Coordinates used here are in the " $X P$ " coordinate system used in R87.

In 1985 and 1986, a structural survey was made of the terminus lobe, with the objective of relating structures to the deformation observed during the surge. This was an unusual opportunity to interpret structures in a setting where the deformation history is known from measure-

\footnotetext{
* Present address: Institute of Arctic and Alpine Research, University of Colorado, Boulder, Colorado 80309, U.S.A.
}

ments. The purpose of this paper is to describe several foliations seen to be the result of the surge, and to compare their occurrence with measured values of total strain.

\section{FINITE STRAIN IN THE TERMINUS LOBE}

The deformation in the terminus lobe during the surge is known from surface measurements and from numerical calculations of compatible deformation at depth (Pfeffer, 1987; R87). While the deformation during the surge was measured at the surface only, the numerical calculations show that almost all of the down-glacier displacement was accomplished by basal sliding, and that shear deformation within the bulk of the ice was small. This conclusion was substantiated at locations farther up the glacier by observations of borehole deformation (Kamb and others, 1985).

Deformation in the terminus lobe occurred essentially as plane strain in a plane oriented vertically and in the direction of flow, with the principal compression in the direction of flow and the principal extension approximately vertical. While small amounts of extension transverse to the flow direction occurred in parts of the terminus lobe, these did not comprise a significant part of the total strain. Daily average longitudinal strain rates were calculated from surveys of stakes placed at $50 \mathrm{~m}$ intervals along a line initially $1.6 \mathrm{~km}$ long and subparallel to the flow direction (R87). Longitudinal strain rates were also measured independently at two locations by $1 \mathrm{~m}$ base-line automatic recording strain meters which 

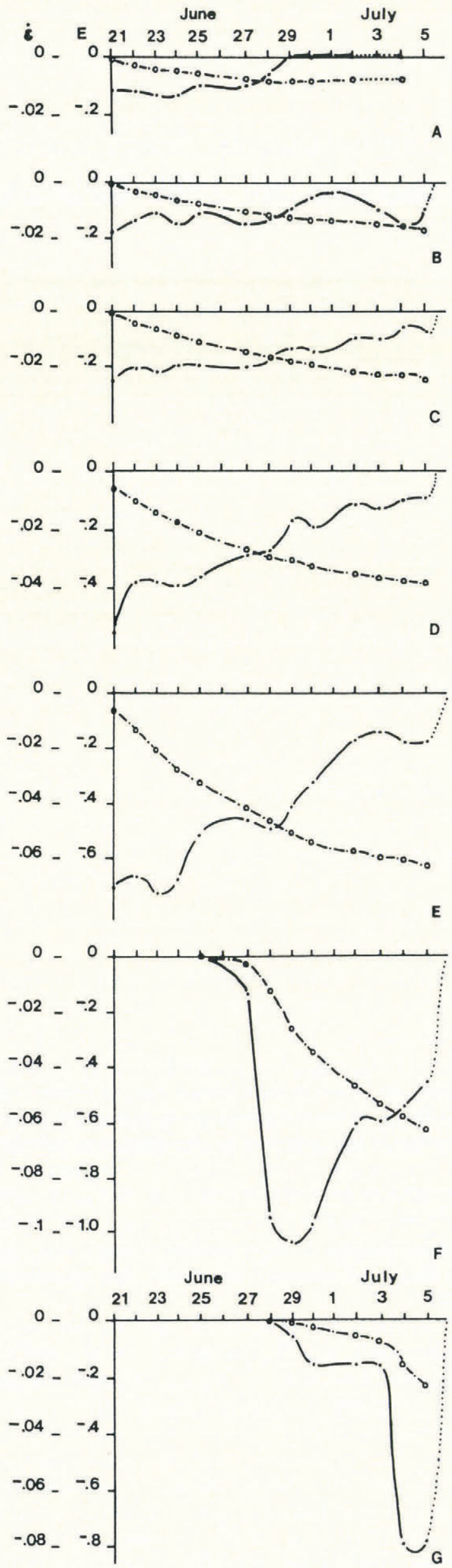

recorded changes in the length of the base line continuously. Because of the very high strain rates which occurred with the passage of the surge front, daily average strains could also be checked simply by measuring the change in strain-meter base line with a tape.

Total strains associated with the passage of the surge front were determined by four methods derived from the survey and strain-meter data. Daily longitudinal surface strains calculated from survey data were co-axial and could be simply summed over the period between 22 June (the onset of surge activity in the terminus lobe) and 5 July (the termination of the surge) 1983. Figure 1 shows the calculated strain rate and accumulated strain for seven sites on the terminus lobe over the interval 21 June5 July 1983. Coordinates for the seven sites given here refer to the final position of the sites following the surge. These sites, labeled A through $\mathrm{G}$, correspond to the $c$-axis fabric sites described in section 3 and marked in Figure 5. Only two sites, $F$ and $G$, near the final position of the surge front were surveyed during the entire interval between the arrival of the surge front and the termination of the surge on $5 \mathrm{July}$. The five sites above $\mathrm{F}$ and $\mathrm{G}$ were already involved in the surge on 21 June when surveying was started. No site on the profile was surveyed for long enough to capture both the arrival of the front and the tail of lower strain rate which followed the initial period of high strain rate. However, a comparison of the sequence of sites gives a general picture of the typical strain history at a single location.

Before the arrival of the front, a typical site shows only very low levels of strain rate. These low levels are not visible in data from data surveys, but can be seen in the automatic strain-rate records. The arrival of the front produces a dramatic rise in compressive strain rate to the maximum levels measured (typically -0.008 to $-0.10 \mathrm{~d}^{-1}$ ) within $1 \mathrm{~d}$ of the onset. This rise may involve an intermediate phase of compression at a lower level, as seen at site $\mathrm{G}$, but such a phase is not always present. Daily averages of velocity result in a smoothing of the onset of high compressive strain rate, but in the automatic records of strain rate it will be seen that the onset of compression may rise from near zero to high levels in the space of a few hours.

Compression at the highest strain rates is maintained for about $1 \mathrm{~d}$, and is terminated by a pronounced drop to levels about half of the maximum value. Thereafter, the compressive strain drops in stages, with short episodes of higher compression, until the strain rate drops essentially to zero, as seen at site $\mathrm{A}$. The drop to zero strain rate occurs not because the ice is stagnant again, but because it is being carried in the central part of the surge zone.

$\triangleleft$ Fig. 1. Calculated longitudinal strain rate $\left(d^{-1}\right)$ and total strain (logarithmic) at seven sites on the terminus lobe, during the time of passage of the surge front through the terminus region. Strains and strain rates are $24 h$ averages calculated from daily surveys of surface markers. Solid line between data points shows strain rate; dot-dash line shows accumulating strain. Dotted line at end of strain-rate curve is estimated tail-off of strain rate following passage of surge front. 
The velocity at site $\mathrm{A}$ when the compressive strain dropped to zero was about $30 \mathrm{~m} \mathrm{~d}^{-1}$.

The magnitudes of strain rate and total strain at the surge front are consistent with a simple kinematic model of deformation in terms of thickness and velocity change across the front. For depth-independent velocity $u$ and plane strain, if $u_{2}$ and $h_{2}$ are the velocity and thickness on the down-glacier side of the surge front, respectively, $u_{1}$ and $h_{1}$ are the same quantities on the up-glacier side of the surge front, and $L$ is the longitudinal length of the front, then the average strain rate across the front

$$
\overline{\dot{\varepsilon}}=\frac{u_{2}-u_{1}}{L} \text {. }
$$

The total longitudinal strain across the front can be found (in the absence of transverse strains) through the vertical extension of a column of ice which starts at the base of the front at thickness $h_{2}$ and ends at thickness $h_{1}$ at the top. Continuity of the column requires that

$$
h_{2} \Delta x=h_{1} \Delta x^{*}
$$

where $\Delta x$ and $\Delta x^{*}$ are the longitudinal dimensions of the column before and after its passage through the front. From this ratio, one finds the ratio of the thicknesses, and the total strain $E$ :

$$
\begin{aligned}
\frac{\Delta x^{*}}{\Delta x} & =\frac{h_{2}}{h_{1}} \\
E=\frac{\Delta x-\Delta x^{*}}{\Delta x} & =1-\frac{h_{2}}{h_{1}}
\end{aligned}
$$

or in terms of logarithmic strain,

$$
E_{\log }=\ln \frac{h_{2}}{h_{1}} .
$$

At the time of the passage of the surge front past $\mathrm{F}$, $\left(u_{2}-u_{1}\right) \approx-22 \mathrm{md}^{-1}$, while $h_{1} \approx 78 \mathrm{~m}, h_{2} \approx 40 \mathrm{~m}$ and $L=365 \mathrm{~m}$. The measured average strain rate in the $9 \mathrm{~d}$ period (26 June- 5 July) measured at $F$ was $-0.069 \mathrm{~d}^{-1}$, while Equation (1) predicts an average strain rate of $-0.060 \mathrm{~d}^{-1}$. The measured total strain (logarithmic) in the same interval was -0.626 , while Equation (2) predicts -0.668 . Earlier, when the surge front was passing through positions higher on the glacier, the surge front had a less distinct topographic ramp. The distance $L$ between the upper and lower limits of the surge front was greater; for example, $2 \mathrm{~km}$ above the terminus lobe, $L \approx 900 \mathrm{~m}$. Also, the front height $h_{1}-h_{2}$ was smaller relative to the total ice thickness, making $h_{2} / h_{1}$ closer to 1 . Equations (1) and (2) indicate that the lower, broader topographic ramp results in a reduction in the predicted total strain and strain rate across the front. This is visible in the sequence of records in Figure 1 and was observed higher on the glacier as well (R87).

A second source of total strain data comes from calculations of total vertical extension derived from total vertical displacement assuming conservation of volume and no transverse strain. This calculation produced total vertical strains which were incompatible with the assumption of conservation of volume and the observed horizontal strains. Observed vertical displacements were greater than those predicted by conservation of volume. Small transverse strains were present but were extensile; compressive transverse strains would be required to account for the excess vertical displacement. It was concluded that dilatation within the glacier was responsible for the excess vertical displacement; this was based in part on an observed settling of the glacier surface by about $12 \%$ of the total thickness in the month following the termination of the surge. This has been discussed further in R87. For the present purpose, a third calculation of total strain was based on vertical extension, with the total thickness change reduced by $12 \%$.

A fourth calculation of total strain was made by integrating the strain-rate signal recorded by the automatic strain meters. Longitudinal strain at the surface was measured by short base-line strain meters at two locations in the terminus lobe during the passage of the front. Finite strains from both records are included in the estimates of total strain in the terminus lobe, but the details of only one site (DX, at $X P=18050)$ are discussed here. Changes in base line were recorded continuously by an LVDT transducer mechanically coupled to two aluminum piers set about $2 \mathrm{~m}$ deep in the ice. The initial length of the base line was $1.4 \mathrm{~m}$ at site DX. Neither the piers nor the strain meter was buried in snow to maintain a constant temperature. This would have been impractical on the terminus lobe, since the snow cover had melted away and was not critical to the measurements because the strain rates were so high. The piers were not actively frozen into the ice. This was generally not a problem since the longitudinal compression kept the piers fixed firmly in place. In brief episodes, however, the piers were forced up out of their holes, or twisted around a vertical axis, causing artifact extensions which were measured and removed in the data reduction. Some gaps in the data were caused by electronic failure or by the LVDT running past its range. In these cases, the missing data could sometimes be replaced by average strain rates derived from direct measurements of strainmeter pier spacing.

Measurements at site DX started before the arrival of the surge front. The onset of compression (Fig. 2) on 16 June is very clear. Prior to the onset of compression, the record shows a very weak but variable strain rate, mostly in extension at $0.001-0.002 \mathrm{~d}^{-1}$. A stronger extension event occurs $2 \mathrm{~d}$ before the onset of compression, during which the strain rate briefly reaches $0.01 \mathrm{~d}^{-1}$. Temperature effects may be the source of the strain rate at these low levels, since higher sites which were buried in snow showed much more stable near-zero strain rates before the onset of compression. Strain rates in the maximum compressive phase reached $\approx-0.13 \mathrm{~d}^{-1}$, and were terminated by a drop late on 17 June, followed by a sequence of lower-level compressive events.

Figure 3 shows total strain from the four sources plotted as a function of down-glacier distance on the terminus lobe. Magnitudes of axial strain are expressed $\operatorname{logarithmically~}\left(E_{\log }=\log \left(l_{\text {final }} / l_{\text {initial }}\right)\right.$, where $l_{\text {initial }}$ and $l_{\text {final }}$ are the initial and final lengths of the deformed line). The magnitude of total strain varies between the four sources, but a common pattern is shared by all: total strain increases in the down-glacier direction to a maximum (at $X P=18200$ ) located about $260 \mathrm{~m}$ behind the final position of the surge front (at $X P=18460$ ), and decreases in that $260 \mathrm{~m}$ to zero just beyond the final 




Fig. 2. Record of strain rate at site $D X(X P=18050)$ from $1.4 \mathrm{~m}$ base-line automatic strain meter.

position of the front, where ice was unaffected by the surge. Strain rates were highest in the first $100 \mathrm{~m}$ of the active surge front, and strain accumulated rapidly in ice as it was first activated by the propagating surge. Total strains in the $260 \mathrm{~m}$ zone behind the final position of the front diminish with down-glacier distance because ice lying nearer to the final front position was involved in the surge for a shorter time. Up-glacier from the position of maximum total strain, the total strain diminishes with upglacier distance despite the fact that all ice in this area had passed through the entire surge-front zone and was in

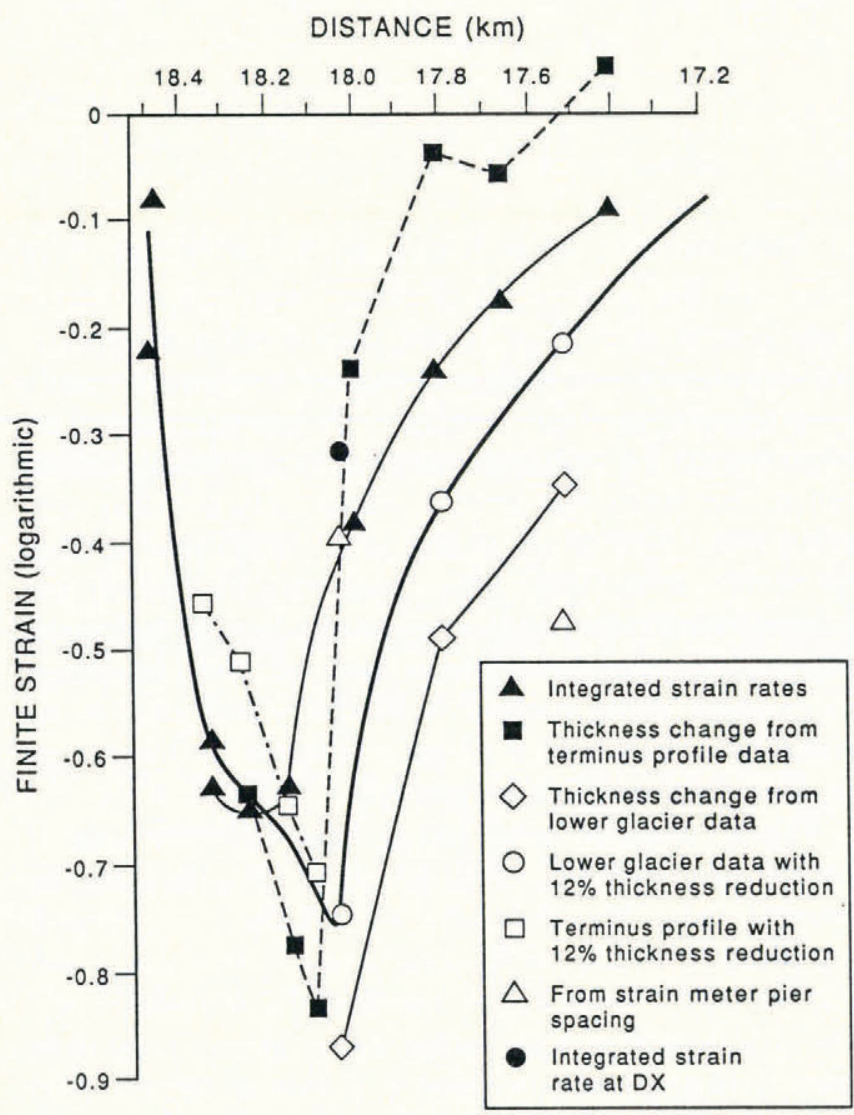

Fig. 3. Profile of total strain in the terminus region calculated from various data sources. The heavy line is the optimum choice of total strain variations. a regime of high velocity and low strain rate. This is a pattern that was observed higher on the glacier as well: the total strain involved in the passage of the surge front diminishes in thicker ice. The kinematic explanation of how total strain is diminished as a consequence of the more gradual geometry of the surge front has been discussed, but the question still remains as to why the front is smaller in thicker ice. This is possibly due to the advance of the surge front being controled by the development of some threshold stress at depth; if the threshold stress is independent of initial thickness, then the thickness change $\left(h_{1}-h_{2}\right)$ required to achieve the threshold stress will be less in already thick ice. This has been discussed further in Pfeffer (1987). Within the terminus lobe, the maximum compressive strain occurred in the initially thinnest ice which experienced the entire passage of the surge front.

The heavy line in Figure 3 joins values of total strain which are the best choice from among the various measures of strain at each position along the profile. In picking the curve, the most reliable estimates are given greater weight. In the upper end of the profile, the calculations based on thickness change reduced by $12 \%$ are used, while at the maximum a mean of the various closely spaced values is used. Below the maximum, the thickness change was not fully developed, and the $12 \%$ reduction in final thickness is less accurate; here the summations of longitudinal strain are used. The averaged value for the maximum compressive strain $260 \mathrm{~m}$ behind the final front position is -0.75 (logarithmic), corresponding to a shortening of $53 \%$. The particular choice of a single profile of total strain from among the various sources is not critical to the arguments that follow; the conclusions would be unaffected if, for example, the maximum or minimum estimated strains were chosen instead of intermediate values.

\section{STRUGTURES OBSERVED IN 1985-86}

\section{Pre-surge conditions and overall conditions in 1985}

Field work was continued following the end of the surge 
in 1983 during the summers of 1984, 1985 and 1986. Not until 1985, however, was the surface of the terminus lobe sufficiently smoothed by ablation to allow easy enough access for a complete structural survey. Old survey markers were found and the sub-region was relocated where the strain data discussed in the last section applies. The structural survey was made in an area between 100 and $200 \mathrm{~m}$ wide covering the old survey profile, now compressed to a length of about $1.3 \mathrm{~km}$. This region, referred to below as the survey region to distinguish it from the entire terminus lobe, was mapped for topography, debris cover, ice type, foliations, fractures and folding. In addition, $c$-axis fabrics were measured in the conventional way described in Langway (1958) and are displayed in Figure 5 as lower hemispheric equal-area projections, contoured using Kamb statistics (Kamb, 1959). In the discussion that follows, reference should be made to Figure 5, which shows the distribution and orientation of the various mapped structures.

Ice throughout the terminus lobe, both below the limit of the 1982-83 surge and above it up to approximately $X P=18200$, is covered with a mantle of debris up to $20 \mathrm{~cm}$ in thickness. Beneath this debris, however, the ice is generally clean, with only occasional stones or dirt clumps appearing in excavations or visible within the ice. The ice above the 1982-83 surge limit is composed of large, elongated, interlocking crystals, roughly $2 \mathrm{~cm} \times 10 \mathrm{~cm}$ with tortuous, branching arms. No fine ice was found in the survey region within the limits of the 1982-83 surge. Some small layers of fine ice were found outside the survey region at two marginal sites.

Ice from beyond the limit of the 1982-83 surge is typically very large-grained $(10-15 \mathrm{~cm})$, and almost entirely bubble-free. This ice has been stagnant since the end of the 1964-65 surge, and has been at $0^{\circ} \mathrm{C}$, except for the annual penetration of the winter cold wave. The large grain-size and absence of significant patterns in caxis orientations are consistent with ice subject to hightemperature annealing. It is notable, however, that $c$-axis fabrics in the area beyond the surge limit are not entirely random, but show very weak maxima in a nearly vertical orientation (Fig. 5; fabrics $\mathrm{G}$ and $\mathrm{H}$ ). This is surprising in the light of Rigsby's (1960) observations on recrystallization of natural fabrics in glacier ice from Greenland, where well-developed maxima were seen to anneal at $0^{\circ} \mathrm{C}$ to a new, random fabric in the space of a month. A significant difference between Rigsby's observations and the present case is that Rigsby was dealing with ice of a very small grain-size (c. 300 grains in a 3 in diameter section) in comparison to the Variegated Glacier ice. The small grain-size would have provided many grain boundaries for nucleation sites for new grains, and may have substantially facilitated the recrystallization process.

No structural survey was conducted in the terminus lobe prior to the 1982-83 surge, so the initial condition of the ice in this region is not known from direct observation. The condition of ice immediately beyond the limit of the 1982-83 surge is taken to be the initial condition of nearby ice which was affected by the surge. This assumption is supported by sharp contrasts between ice structures beyond and within the limit of the 1982-83 surge, together with the fact that the location of this limit is distinguished only by the presence of the final position of the surge front, and not by any topographic or dynamic feature prior to the surge.

Four distinct penetrative structures appear in the part of the terminus lobe affected by the 1982-83 surge. Two are interpreted as existing before the surge; a subhorizontal layering distinguished especially by dirt and debris horizons and identified as primary depositional layering $\left(\mathrm{S}_{0}\right)$; and a well-developed sub-horizontal foliation $\left(\mathrm{S}_{\mathrm{b}}\right)$ appearing in the deepest exposed ice just beyond the final position of the 1982-83 surge front. Two other foliations are interpreted as having formed as a consequence of the passage of the surge front: a ubiquitous transverse striking, vertically dipping bubble-density foliation $\left(\mathrm{S}_{1}\right)$ and an intermittent but closely spaced $(\mathrm{c} .20 \mathrm{~cm})$ fracture set $\left(\mathrm{S}_{2}\right)$ which strikes in the local flow direction and is vertically dipping. Figure 5 shows the orientation and trend of $S_{1}$ and $S_{2}$ in the survey region.

$\mathrm{S}_{0}$ is a ubiquitous, sub-horizontal, wavy or undulatory layering, demarcated by bubble-density variations and debris horizons. The debris horizons range in thickness from interfacial dirt to layers up to $10 \mathrm{~cm}$ thick, and can contain cobbles up to $10 \mathrm{~cm}$ in size. Individual layers of $\mathrm{S}_{0}$ are typically $10-20 \mathrm{~cm}$ thick. The wavy character of the layering is defined by fold axes striking across the glacier in a direction perpendicular to the ice flow. Above the terminus lobe, folding of $\mathrm{S}_{0}$ is about axes striking approximately in the flow direction. The sense of folding is consistent with observed patterns of longitudinal extension and transverse compression in the confined channel up-glacier from the terminus lobe, and longitudinal compression and transverse extension in the terminus lobe. $\mathrm{S}_{0}$ is cut by all other planar structures observed, and is folded wherever folding of any structure is present. $S_{0}$ is evidently the earliest generation of structure present in the terminus lobe, and is believed to be the primary depositional layering. This identification is supported by the ubiquitous occurrence of $\mathrm{S}_{0}$, its subhorizontal orientation, abundant accumulations of debris, and the fact that the deformation associated with periods of surging allows structures to be carried long distances down-glacier with little alteration. At Variegated Glacier, a structure formed in the central part of the glacier will be carried farther by surging motion in 1 year of the 20 year surge cycle than by ordinary motion during the remaining 19 years. During the surge, the deformation behind the surge front is characterized by rapid basal sliding with little deformation in the main body of the glacier, so that ice and the structures in it can be transported long distances with very little of the deformation associated with structures seen in the termini of non-surging glaciers. About three surge cycles are required to carry ice from the central section of Variegated Glacier to the terminus. Accordingly, ice flows in a normal mode for a total of about 57 years at moderate strain rates (Raymond and Harrison, 1988) and in a seasonal surging mode for about 3 years at high strain rates, but low total strains (viz. Fig. 1), in its course from mid-glacier to the terminus. The accumulated total strain in ice arriving at the terminus is small compared to the termini of non-surging glaciers, and depositional layering can appear at the terminus relatively intact, with only minor, small-scale deformation. 
$\mathrm{S}_{\mathrm{b}}$ is exposed in a run-off stream channel $240 \mathrm{~m}$ beyond the limit of the 1982-83 surge. This strong subhorizontal bubble foliation appears with a very diffuse $c$ axis fabric with poles oriented approximately perpendicular to the plane of foliation (Fig. 5; region VII). This foliation and fabric is in the deepest ice exposed at the surface (either before or after the 1982-83 surge). The thickness of the ice here is less than $40 \mathrm{~m}$, and the subhorizontal foliation may be the result of basal shear during the 1964-65 surge (this ice experienced essentially no motion since the 1964-65 surge, and was sufficiently active during that surge that any pre-existing structures near the bed are unlikely to have been preserved). This foliation is irregular in orientation, and has evidently been deformed since its formation as ice has flowed into local topographic lows such as old crevasses. The $\mathrm{S}_{0}$ foliation appears to be the product of large shear strain parallel to the bed, probably during the 1964-65 surge, when ice in this area was last active. The ice exposed at the surface at this place in 1986 was very near the bottom of much thicker ice in the past. It is reasonable to suppose that ice so near the bed of the glacier may have been included in a narrow zone of intense basal shear under a surge front in much thicker ice during the 1964-65 surge.

The $c$-axis fabrics at sites $\mathrm{G}$ and $\mathrm{H}$ (Fig. 5) are taken from ice containing the $S_{b}$ foliation. The intensity of $S_{b}$ is moderate at $G$ and very strong at $\mathrm{H}$. The contour diagrams faintly suggest multiple maximum (possibly three-pole) orientations. The maxima on the contour plots at these sites are three standard deviations above a random distribution, above the two standard-deviation criterion for significance, but are much less strong than maxima appearing at sites above the 1982-83 surge limit.

$S_{1}$ is a bubble foliation set in vertical planes striking transverse to the direction of flow. This foliation is not as well developed as some classic examples of longitudinal foliation (e.g. Allen and others, 1960), and does not have a continuous laminated structure, although such welldeveloped foliation was seen at other parts of the glacier. Rather, $S_{1}$ consists of closely spaced flat clusters of bubbles approximately $20 \mathrm{~cm}$ in the transverse (crossglacier) direction and $2 \mathrm{~cm}$ in the longitudinal (downglacier) direction, giving an axial ratio in the horizontal

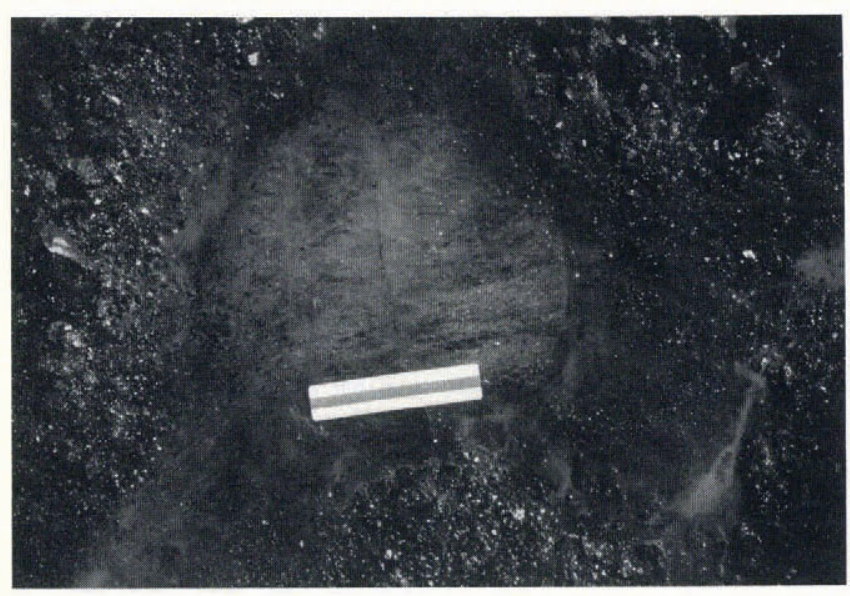

Fig. 4. Photograph of $S_{1}$ and $S_{2} . S_{1}$ strikes parallel to the scale; an $S_{2}$ crack cuts across $S_{1}$ perpendicular to the scale. The scale is $15 \mathrm{~cm}$ long. plane of $1: 10$. Many closely spaced bubble clusters of this shape set in otherwise bubble-free ice produce an easily recognized, orientable foliation. The foliation is difficult to photograph. If one closes one eye when looking at $S_{1}$, the perception of the boundaries between bubbly and clear ice is diminished, and much of the strength of the foliation is lost. The same effect occurs in a photograph. This effect also made it difficult to measure the axial ratio very precisely, although the same estimate $(1: 10)$ was arrived at independently by another observer (personal communication from W. Lawson).

$\mathrm{S}_{2}$ is a pervasive set of hairline cracks, dipping vertically and striking in the longitudinal direction. Generally, fine bubble trains surround and extend from the ends of the cracks, and sometimes appear alone without a crack. In addition to the hairline cracks, small crevasses exist in the $S_{2}$ orientation, usually occurring in longitudinally elongated fields about $10 \mathrm{~m}$ in length. The crevasses are as wide as $10 \mathrm{~cm}$ and up to about $3 \mathrm{~m}$ long, with depths roughly equal to their length. Figure 4 shows a typical exposure of $S_{1}$ and $S_{2}$.

\section{Longitudinal distribution of folia and $c$-axis fabrics}

The orientation and abundance of $S_{1}$ and $S_{2}$, the two foliations which intersect the surface, is shown in rosettes at the top of Figure 5. The survey region has been subdivided into seven regions, labeled I through VII. Within each sub-region, the average orientation and standard deviation of $S_{1}$ and $S_{2}$ data are plotted. The width of the rosette bar represents the standard deviation in strike, and is centered on the average strike. The length of the rosette bar from the center is proportional to the abundance of data, with all rosettes plotted to the same scale. The data counted in determining the plotted abundance are the number of observations within a sub-region. Each sub-region was mapped at a consistent level of detail, so that the abundance of data is not a total count of individual folia, but a measure of the intensity and extent of the foliation within a sub-region. Similarly, the mapped lines representing $S_{1}$ on Figure 5 are not traces of individual folia but indicate both the local orientation and intensity of $\mathrm{S}_{1}$ foliation within each subregion. Individual $S_{2}$ structures on the map represent individual observations, and again are not a total count of individual structures but a measure of the orientation and distribution within a sub-region.

Ice at the up-glacier end of the survey region and above is uniformly bubbly and milky in appearance. The bubble-density variations which define $S_{1}$ are absent. $S_{1}$ becomes visible only further down into the terminus lobe (near $X P=17550$ ), where it becomes pervasive. It persists throughout the middle and lower survey region until part-way down the topographic ramp that defines the final position of the surge front. The visibility of $S_{1}$ varies somewhat where it exists, but tends to intensify somewhat in the down-glacier direction, and is traceable anywhere (in many places only after washing away the debris cover) until its disappearance at the surge front. About half-way down the topographic ramp, $\mathrm{S}_{1}$ vanishes over a zone about $5 \mathrm{~m}$ wide, running transversely across the glacier. The presence of $S_{1}$ on one side of this zone and 


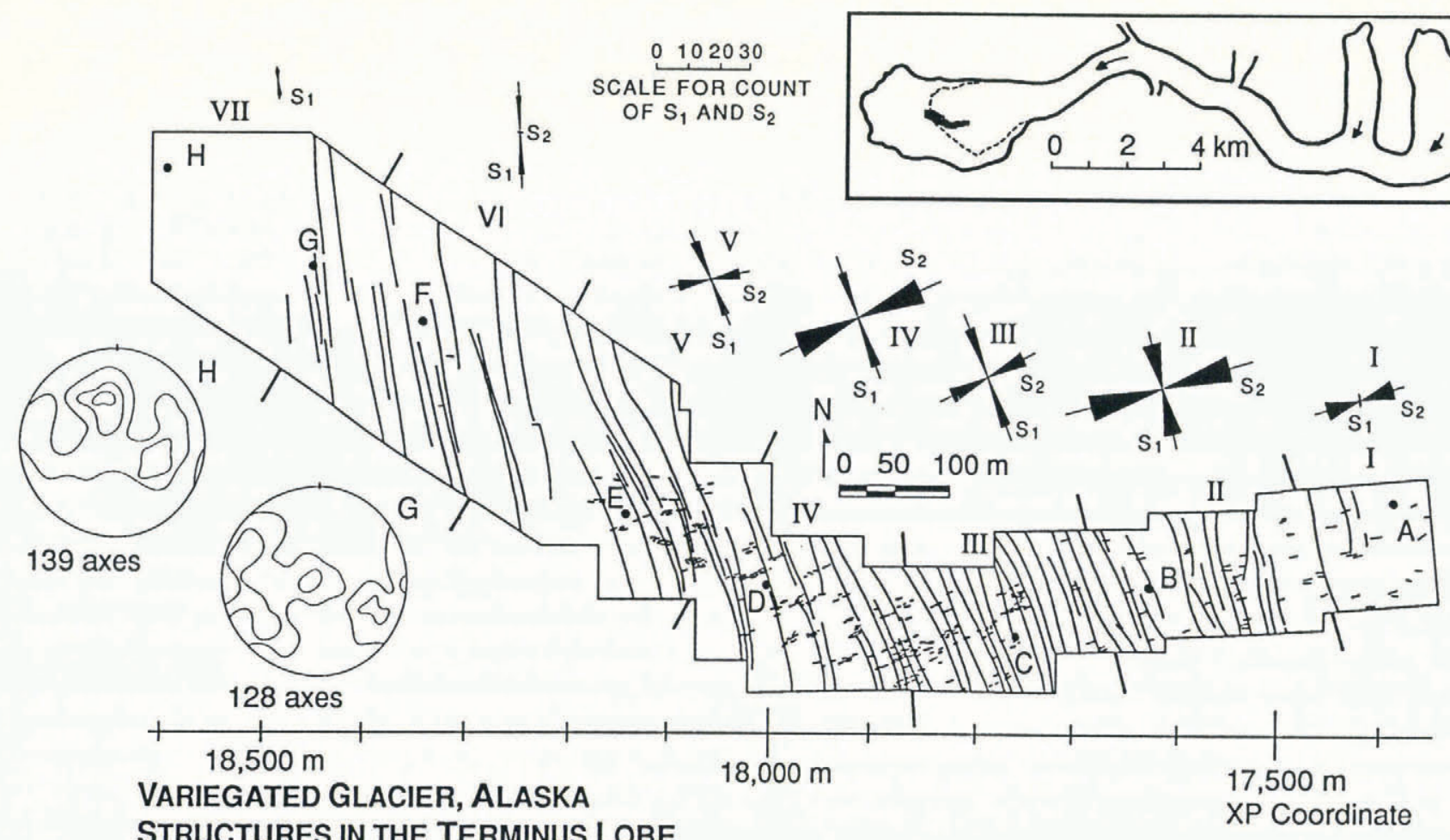

\section{STRUCTURES IN THE TERMINUS LOBE FOLLOWING THE 1982/83 SURGE}

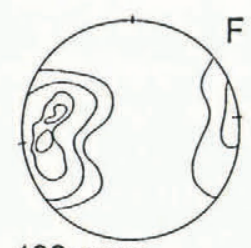

133 axes

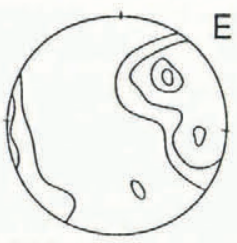

115 axes

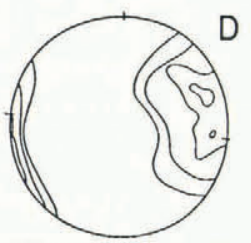

99 axes

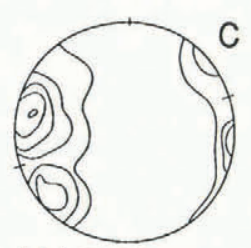

144 axes



109 axes

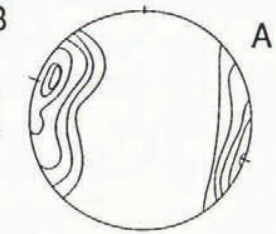

105 axes

FABRIC CONTOUR INTERVAL $3 \sigma$

Fig. 5. Map of structures observed in the survey region. Trends and density of $S_{1}$ and $S_{2}$ are shown in plan. Presentation of the data is discussed in the text.

absence on the other was verified by an especially dense sampling of sites.

The $S_{1}$ foliation evidently develops during the passage of the surge front, on the topographic ramp where both stress and strain rate are very high (e.g. typical values at the front in the lower survey region are $\dot{\varepsilon} \approx-0.125 \mathrm{~d}^{-1}$ (Lagrangian) and $\sigma \approx 0.6 \mathrm{MPa}$; from R87; Fig. 4). The topographic front was roughly $400 \mathrm{~m}$ in the longitudinal direction at its final position, and immediately prior to the termination of the surge was propagating at approximately $26 \mathrm{~m} \mathrm{~d}^{-1}$. At this rate, the surge front would traverse the $5 \mathrm{~m}$ zone where $S_{1}$ appears in under $4 \mathrm{~h}$, and would traverse the entire topographic ramp in slightly more than $15 \mathrm{~d}$. It is not known that the zone across which $S_{1}$ developed propagated at the same speed as the features whose propagation was observed, or that the zone remained constant in width. A conservative estimate for the time of formation of $S_{1}$ is within the $15 \mathrm{~d}$ interval occupying the passage of the topographic front.

A run-off stream exists flowing transversely at the foot of the ramp $240 \mathrm{~m}$ beyond the zone where $\mathrm{S}_{1}$ disappears. In exposures cut by this stream, the very distinct $\mathrm{S}_{\mathrm{b}}$ foliation is obvious. $S_{b}$ can be traced back up-glacier from the stream exposures to the zone where $S_{1}$ disappears. $S_{b}$ persists with a progressive weakening of the intensity of foliation, but is still easily traceable up-glacier in continuous exposures of another stream channel, until it vanishes abruptly at the down-glacier edge of the zone where $S_{1}$ disappears. Within the zone itself, a very vague organization of bubble density is present. Amorphous, ropey structures are discernible but have no planar structure.

$\mathrm{S}_{2}$ is present at the up-glacier limit of the survey region, somewhat scattered in orientation, but confined to within about $10^{\circ}$ of the flow direction. By the middle part of the survey region (sub-region II through $\mathrm{V}$ ), strikes are quite consistent locally, with some variation occurring in organized patterns. The frequency of appearance of $\mathrm{S}_{2}$ features diminishes in the lower part of the survey region (sub-region V) and ultimately dies out several hundred meters above the final position of the surge front (subregions VI and VII).

A consistent pattern appears in the $c$-axis fabrics (Fig. 5 ) in the sequence of sites from A to F. All show a broad, elongated maximum, pointing approximately in the direction of principal compression and having only a slight dip in the up-glacier or down-glacier direction. The strike of the principal compression direction (from survey data) is designated on individual fabric plots by ticks on the equator. The statistical validity of the $c$-axis is evident 
in the contour diagrams, where the center of the maxima are seen to lie between 9 and $15 \sigma$ above a random distribution. The existence of double maxima at sites $\mathrm{C}$, $\mathrm{D}, \mathrm{E}$ and $\mathrm{F}$ are somewhat less certain, for the weaker maxima at each site stand only three standard deviations above the area separating them from the main maxima. An examination of the scatter plots for these sites does not always reveal convincing secondary maxima. It is questionable whether the orientation of the maxima can be specified very precisely. The maxima are broad and, if the multiple maxima are regarded as one diffuse maximum, the orientation becomes even less definite. An eigenvalue decomposition of the orientation distributions would provide principal directions of a best-fit ellipsoid to these data, but this technique is inappropriate for distributions with less than orthorhombic symmetry.

The relation between the orientation of the $c$-axis fabric and the direction of principal compression is striking when compared to the fabrics presented by Kamb (1972) for uniaxial compression and pure shear at $0^{\circ} \mathrm{C}$. $\mathrm{Kamb}$ deformed ice at $0^{\circ} \mathrm{C}$ in an apparatus designed to impose plane strain, but pressure melting of the sample resulted in a strain more nearly resembling uniaxial compression. Ice taken from the base of an icefall at Blue Glacier, Washington, had been deformed in a state closer to pure shear, although some extension in the intermediate strain direction is known to have occurred (personal communication from C.F. Raymond). The state of stress at the surge front in the terminus lobe is very nearly pure shear, being plane strain with the principal compression direction horizontal, principal extension vertical, and only small amounts of extension in the lateral direction. In his experiments and in ice taken from Blue Glacier, Kamb found small-circle fabrics approximately centered on the direction of principal compression (Kamb, 1972, fig. 17). The small circles were incomplete, and appeared rather as two maxima lying adjacent to the principal compression direction. The strength of the maxima at sites $\mathrm{A}$ through $\mathrm{F}$ in the survey region lie intermediate between Kamb's maxima, being stronger than his experimentally produced fabric (at 4-6\% per $1 \%$ area vs $3 \%$ per $1 \%$ area) and weaker than the maxima at Blue Glacier ( $4-6 \%$ vs $8 \%$ ). It should be recalled, however, that some dispersion of $c$-axes may have occurred between the end of the surge in 1983 and the measurements in 1985 and 1986.

The total strain in Kamb's experimentally produced fabric $(-0.37$ logarithmic) was less than the likely total strain in the Variegated Glacier terminus lobe. The total strain in the Blue Glacier sample was unknown, but a strain rate of about 0.3 year $^{-1}$ (logarithmic, pure shear) was measured over lyear. The grain-size in the experimentally deformed sample was small $(0.5-0.9 \mathrm{~mm}$ diameter), and grew to a larger diameter, but still was substantially smaller than what was observed at Variegated Glacier. The Blue Glacier ice type was described only as coarse bubbly, but was probably comparable in grain-size to the ice at Variegated Glacier.

The orientation and pattern of fabric maxima at sites A through $\mathrm{F}$ indicate that some complex maximum or maxima developed roughly co-axially with the direction of principal compression. The fabrics are similar to $\mathrm{Kamb}$ 's fabrics for compression at $0^{\circ} \mathrm{C}$ and give support to the idea that these fabrics are typically associated wtih pure shear.

\section{RELATION OF $S_{1}$ AND $S_{2}$ TO STRESS AND FINITE STRAIN}

The appearance of the amorphous bubble distribution in the transition zone between $\mathrm{S}_{1}$ and $\mathrm{S}_{\mathrm{b}}$ suggests that $\mathrm{S}_{\mathrm{b}}$ is being destroyed by some strain- or stress-related process which simultaneously produces $S_{1}$ as the surge front moves down-glacier. Before the surge, the transition zone lay in a rather flat part of the terminus lobe, undistinguished by any topographic feature. The 1964 65 surge extended past this point. Ice near the transition zone containing the $\mathrm{S}_{1}$ foliation lay at a higher elevation than ice containing $\mathrm{S}_{\mathrm{b}}$ at the time of the survey, but was brought to that elevation by vertical extension at the time of the passage of the 1982-83 surge front.

Hooke and Hudleston (1978) considered foliation to be the product of passive deformation of some pre-existing inhomogeneity rather than the result of bubble migration in the ice. If deformation is to be the source of $\mathrm{S}_{1}$, however, the strains associated with the passage of the surge front should be comparable to the strains required to produce $\mathrm{S}_{1}$.

The initial state of the ice is not precisely known. The $\mathrm{S}_{\mathrm{b}}$ foliation on the down-glacier side of the $\mathrm{S}_{1} / \mathrm{S}_{\mathrm{b}}$ transition is probably not typical of the initial state, for $\mathrm{S}_{1}$ appears throughout the lower terminus lobe, while $\mathrm{S}_{\mathrm{b}}$ is evidently limited to ice near the bed of the glacier. A better choice for a representative of the pre-surge condition is the patchy, inhomogeneous bubble distribution in the $S_{1} / S_{b}$ transition zone. $S_{o}$ would also be present initially, but is present after the formation of $S_{1}$ as well, and evidently has no direct bearing on the formation of $S_{1}$.

If the $S_{1}$ foliation is to be created from isotropic patches of bubbles, the compressive strain required to produce the observed horizontal axial ratio of $1: 10$ in the resulting folia is -2.3 (logarithmic), assuming plane strain in a vertical longitudinal plane. This is much more strain than was observed in the surge front, where the maximum compression was -0.75 . The longitudinal strain required to produce a $1: 10$ axial ratio in a horizontal plane can be reduced by assuming other modes of strain: in uniaxial compression a strain of -1.53 is required, and in horizontal plane strain only -1.15 is required. These are still substantially greater than the observed strain and, in any case, are not plausible modes of deformation given that only very small lateral extensions were observed. Furthermore, the transition zone where $\mathrm{S}_{1}$ disappears (or equivalently, where it first appears during the passage of the surge front) is not located where the maximum strain occurred, but $400 \mathrm{~m}$ further down-glacier, where the total compressive strain was only -0.1 .

Rejecting for the moment the possibility that bubble migration is involved in the formation of $S_{1}$, the only remaining possibilities are that the estimated axial ratic of $1: 10$ is incorrect, or that the initial state of the ice was not isotropic. It must be emphasized that the estimated axial ratio is approximate, although it was reached independently by two observers. The discrepancy in strain cannot 
be ascribed simply to faulty estimates, however, since the maximum observed strain of -0.75 would produce an axial ratio of only $1: 2.1$, which is entirely outside the range of ratios which reasonably represent the anisotropy of the observed foliation. As to the possibility that the $S_{1}$ foliation existed prior to the 1982-83 surge, it is emphasized again that the only two ice types seen outside the limit of the 1982-83 surge are nearly bubble-free ice, and ice containing the $\mathrm{S}_{\mathrm{b}}$ foliation, which is opposite in orientation to $S_{1}$, and could not be transformed to $S_{1}$ simply by a rather small amount of passive deformation in pure shear. The very abrupt zone across which $S_{1}$ vanishes, together with its location coincident with the final position of the surge front (a position undistinguished by any special topographic feature before the surge), is strongly suggestive, but not a proof of causality. Nevertheless, the formation of $S_{1}$ by the action of the surge front remains the simplest explanation of the $S_{1}$ boundary. In the absence of a plausible mechanism of formation of $S_{1}$ by total strain, bubble migration is the remaining choice for the origin of $\mathrm{S}_{1}$. The mechanism of bubble migration is considered further in section 5 .

The orientation and consistency of $\mathrm{S}_{2}$ indicates that these features are fractures formed in response to transverse lateral extension or longitudinal compression, or both, in the surge front. The propagating surge front first developed a well-defined topographic ramp as it passed through the upper and middle parts of the survey region, and this may be an expression of a large-scale organization of stress which also produced the $\mathrm{S}_{2}$ cracks with locally consistent strikes. $\mathrm{S}_{2}$ cracks were observed during the surge on 2 July 1983, in an orientation perpendicular to the observed direction of maximum extension (R87). Rather than being related to a direction of maximum total strain, $S_{2}$ is created perpendicular to the orientation of maximum extensile strain rate (and, accordingly, stress) which caused the rapid development of a pervasive set of cracks and crack-related features.

\section{DISCUSSION}

Stress-induced bubble migration in ice is a poorly understood phenomenon and, while it has been discussed as a possible mechanism for producing bubble-density foliation (Hooke and Hudleston, 1978), it has never been shown to be a likely mechanism under normal glacierflow conditions. Rotation of pre-existing inhomogeneities has been generally accepted as the source of foliation in glacier ice (Hooke and Hudleston, 1978; Hambrey and others, 1980; Hudleston and Hooke, 1980). In the present case, however, an inhomogeneous bubble-density distribution has developed, together with a significant $c$-axis fabric, in a very short space of time, in ice which has not experienced sufficient finite strain to account for the observed anisotropy of bubble content. Kamb's (1972) experiments on recrystallization include some experiments which are strikingly similar to the situation at the Variegated Glacier terminus lobe, as discussed above, but which possess further similarities in connection with the question of foliation developed rapidly by bubble migration.
Kamb's (1972) experiments include two tests in pure shear at $0^{\circ} \mathrm{C}$, at high compressive stress (experiments $\mathrm{Cl}$ and C4, table 1 of $\mathrm{Kamb}(1972)$ ). One of these tests was conducted at a compressive stress of $0.64 \mathrm{MPa}$ for $2.3 \mathrm{~d}$, to a finite compressive strain of -0.31 (Lagrangian) or -0.37 (logarithmic). This is close to the strain history of ice at the Variegated Glacier terminus during the production of $\mathrm{S}_{1}$, where the compressive stress was approximately $0.6 \mathrm{MPa}$, and lasted for a period less than $15 \mathrm{~d}$, during which the total strain accumulated to no more than -0.75 (logarithmic). Kamb's test, which ran for a shorter time and to a smaller total strain than was experienced by ice in the terminus lobe, developed a significant $c$-axis fabric (Kamb, 1972, figure 17(a)) which is very similar in structure to the fabrics at sites $\mathrm{A}$ through $\mathrm{F}$ in the survey region (Fig. 5). Moreover, Kamb stated that bubbles migrate through the ice in experiments at $0^{\circ} \mathrm{C}$, but did not elaborate. He reported later, however, (personal communication, 1990) that bubbles were initially distributed uniformly in the sample, and migrated into a band perpendicular to the direction of applied stress. In the final state, the bubbles in the sample were confined to a band about equal in width to the surrounding bubblefree area.

While bubble migration was not directly observed at Variegated Glacier, the $S_{1}$ foliation developed under conditions which do not allow for development by "conventional" means, i.e. by accumulated finite strain, and the work of $\mathrm{Kamb}$ indicates that the process of bubble migration occurs in ice under tectonic conditions such as existed in the Variegated Glacier terminus, and act at a rate which can produce bubble-density distributions and associated $c$-axis fabrics of the type observed at Variegated Glacier.

The other penetrative structure associated with the passage of the surge front in the Variegated Glacier terminus, $\mathrm{S}_{2}$, also developed independently from total strain, but is a penetrative fracture set created at the time of maximum extensile strain rate in the cross-glacier direction. Both are examples of penetrative structures developed under conditions dictated by the state of stress. A glacier surge is an unusual situation, however, and one would not reject the general understanding of foliation on glaciers under normal flow conditions on the basis of these observations. It is shown here, though, that total strain is not the only mechanism by which penetrative structures in general and foliation in particular can form. The unusual state of stress dealt with in this discussion will have a bearing on other studies of structure associated with surging, and possibly with icefalls or other parts of normally flowing glaciers where anomalously high stresses exist.

\section{ACKNOWLEDGEMENTS}

The author thanks Dr C. F. Raymond for guidance and extensive discussions throughout this project. W. B. Kamb has provided essential supplemental information to his 1972 publication. All of the people involved in the Variegated Glacier project between 1980 and 1986 have contributed in a variety of ways, but the author would like to thank especially J. Harbor and M. Lockwood, who 
assisted with the mapping during 1985 and 1986. This work was supported by U.S. National Science Foundation grant No. EAR8512171.

\section{REFERENCES}

Allen, C. R., W. B. Kamb, M. F. Meier and R. P. Sharp. 1960. Structure of the lower Blue Glacier, Washington. 7. Geol., 68(6), 601-625.

Bindschadler, R., W. D. Harrison, C. F. Raymond and R. Crossen. 1977. Geometry and dynamics of a surge-type glacier. J. Glaciol., 18(79), 181-194.

Hambrey, M.J., A. G. Milnes and H. Siegenthaler. 1980. Dynamics and structure of Griesgletscher, Switzerland. f. Glaciol., 25(92), 215-228.

Hooke, R. LeB. and P.J. Hudleston. 1978. Origin of foliation in glaciers. F. Glaciol., 20(88), 285-299.

Hudleston, P.J. and R. LeB. Hooke. 1980. Cumulative deformation in the Barnes Ice Cap and implications for the development of foliation. Tectonophysics, 66(1-3), $127-146$.

Kamb, W.B. 1959. Ice petrofabric observations from Blue Glacier, Washington, in relation to theory and experiment. 7. Geophys. Res., 64(11), 1891-1909.
Kamb, W. B. 1972. Experimental recrystallization of ice under stress. In Heard, H. C., I. Y. Borg, N. L. Carter and C.B. Raleigh, eds. Flow and fracture of rocks. Washington, DC, American Geophysical Union, 211241. (Geophysical Monograph 16.)

Kamb, W. B. and 7 others. 1985. Glacier surge mechanism: 1982-1983 surge of Variegated Glacier, Alaska. Science, 227 (4686), 469-479.

Langway, C. C., Jr. 1958. Ice fabrics and the universal stage. SIPRE Tech. Rep. 62.

Pfeffer, W. T. 1987. Structure and deformation in a propagating surge front. (Ph.D. thesis, University of Washington.)

Raymond, C. F. and W. D. Harrison. 1988. Evolution of Variegated Glacier, U.S.A., prior to its surge. 7 . Glaciol., 34(117), 154-169.

Raymond, C.F., T. Johannesson, T. Pfeffer and M. Sharp. 1987. Propagation of a glacier surge into stagnant ice. 7. Geophys. Res., 92(B9), 9037-9049.

Rigsby, G. P. 1960. Crystal orientation in a glacier and in experimentally deformed ice. F. Glaciol., 3(27), 589606.

The accuracy of references in the text and in this list is the responsibility of the author, to whom queries should be addressed. 